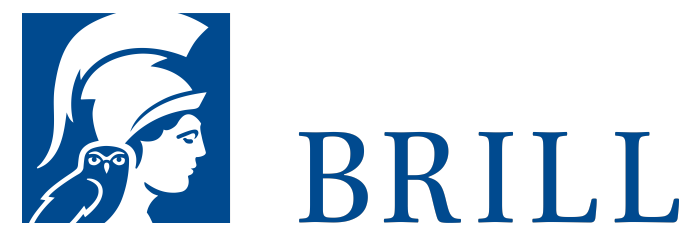

\title{
Kulturgeschichte und aufklärerisches Projekt
}

\author{
Author: Rüdiger Landfester
}

Aufklärung - inzwischen postmodern überholt und damit Geschichte geworden oder womöglich sogar ein zivilisatorischer Irrweg, der zu kritischer Bestreitung und mehr oder weniger radikaler Umkehr Anlass gibt? In dieser Abhandlung mit allgemeinphilosophischen Begründungs- und kulturwissenschaftlichen Zugangsvorschlägen sowie Überblicken über die Entwicklung der europäischen Philosophie, Literatur, Kunst und Musik seit ihren Anfängen lädt der Verfasser dazu ein, sich bei allen Bemühungen um ein differenzierenderes Bild im Einzelnen auch einmal mehr wieder ihrer allgemeineren Linien zu vergewissern. Ihm liegt hierbei zudem insbesondere daran, auf das sie vor allem anderen auszeichnende Ringen um Aufklärung im Sinne von Kants Diktum vom »Ausgang des Menschen aus seiner selbstverschuldeten Unmündigkeit « zu verweisen. Dass es dabei nicht nur um vernunftbegründete Erkenntnis und Bildung geht, sondern auch um Rechtstaatlichkeit und Demokratie, gibt einem solchen Anliegen auch in dieser Hinsicht noch immer eine bleibende Aktualität.

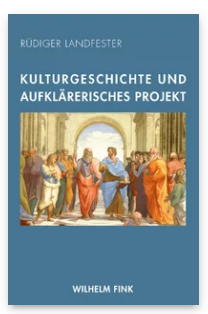

Pages: 560

Seiten, $55 \mathrm{~s} / \mathrm{w}$

Abb.

Language:

German

Subjects:

Cultural History,

Literature and

Cultural Studies

Publisher: Brill |

Fink

E-Book (PDF)

Released online:

O4 Sep 2017

ISBN: $978-3^{-}$

8467-6253-O

List price

Paperback

Publication date:

14 Jul 2017

ISBN: 978-3-

7705-6253-4

List price 
Rüdiger Landfester studierte Philosophie, Geschichte und Politikwissenschaft sowie Germanistik und Romanistik in Freiburg und an der FU Berlin. Er machte den Abschluss mit Staatsexamen für das höhere Lehramt und promovierte im Fach Geschichte. Nach einigen Jahren als Wissenschaftlicher Assistent am Historischen Seminar der Universität Freiburg übernahm er eine Professur für das Fachgebiet Allgemeine Soziologie und Politikwissenschaft an der Hochschule für öffentliche Verwaltung/University of Applied Sciences in Kehl.

For more information see brill.com

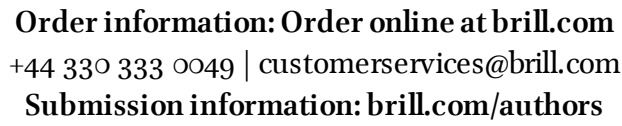

Titles published by Brill | Fink, Brill | mentis or Brill | Schöningh: +49(o)71 5413279216 | brill@brocom.de 